\title{
Representaciones de Simón Bolívar en el centenario de su muerte en la revista Cromos en 1930
}

Andrea Cadelo ${ }^{1}$

Recibido: 04/03/2019

Aprobado por pares: 10/06/2019
Enviado a pares: $18 / 03 / 2019$

Aceptado: 16/07/2019

DOI: $10.5294 /$ pacla.2019.22.4.3

Para citar este artículo / to reference this article / para citar este artigo

Cadelo, A. (2019). Representaciones de Simón Bolívar en el centenario de su muerte en la revista Cromos en 1930. Palabra Clave, 22(4), e2243. D0I: https://doi.org/10.5294/ pacla.2019.22.4.3

\section{Resumen}

Este artículo analiza las representaciones construidas, con ocasión del centenario de la muerte de Simón Bolívar en el número especial que a esta celebración dedicara la revista Cromos, el 13 de diciembre de 1930. A partir del análisis de quince textos que, en su mayoría provienen de autores de la Academia Colombiana de Historia, se discuten las implicaciones de la heroización de Bolívar para el proceso de construcción simbólica de la nación y, más ampliamente, del continente americano, respecto del tiempo, el espacio y la población. Haciendo particular hincapié en el papel que España y América desempeñan en la representación del héroe, se pone de manifiesto la manera como la ovación a Bolívar constituye a su vez una oda a España desde el punto de vista histórico, cultural y racial, mientras que su americanismo se resalta desde el punto de vista geográfico y político. Se demuestra que la exaltación de la capacidad épica del Libertador iba de la mano de esfuerzos genealógicos para evidenciar la pertenencia de Bolívar a la raza blanca europea y para presentar el proceso de independencia, por él liderado, como una fase más de la misión civilizadora que, desde la Conquista,

1 https://orcid.org/0000-0002-9610-3885. Pontificia Universidad Javeriana, Colombia. acadelo@javeriana.edu.co 
España había iniciado en América. El artículo concluye que la heroización de Bolívar llevaba ínsito un desprecio por el pasado prehispánico y un desconocimiento de toda historia previa a 1492, así como una representación denigratoria de sus contemporáneos. Asimismo, concluye que, en sintonía con el republicanismo de la revista, el Bolívar de Cromos es, en general, un Bolívar republicano.

\section{Palabras clave (Fuente: tesauro de la Unesco)}

Simón Bolívar; Bolívar; Cromos; memoria colectiva; nación; raza; identidad; representaciones; hispanismo. 


\section{Representations of Simón Bolívar on the Centenary of his Death in Cromos in 1930}

\section{Abstract}

This article explores some representations of Simón Bolívar, on the occasion of the centenary of his death, contained in a special issue that Cromos magazine dedicated to this commemoration on December 13, 1930. From the analysis of fifteen writings authored mostly by members of the Colombian Academy of History, the implications of heroizing Bolívar for the symbolic building of the nation and, more broadly, the American continent are discussed regarding time, space and population. Emphasizing the role that Spain and America play in the representation of the hero, it is noted how an ovation to Bolívar becomes an ode to Spain from the historical, cultural and racial point of view, while his Americanism stands out geographically and politically. It is shown that the praise for the Liberator's epic abilities is accompanied by genealogical efforts to prove that he belonged to the $\mathrm{Eu}$ ropean white race and to present the process of independence led by him as another phase of the civilizing mission that, since the Conquest, Spain had started in America. In short, the heroization of Bolívar entails disregard for the pre-Hispanic past and ignorance of the history prior to 1492, as well as a denigrating representation of his contemporaries. It is also concluded that, in line with the republicanism of the magazine, Cromos's Bolívar is generally a republican Bolívar.

\section{Keywords (Source: Unesco Thesaurus)}

Simón Bolívar; Bolívar; Cromos; collective memory; nations; race; identity; representaciones; hispanism. 


\section{Representações de Simón Bolívar no centenário de sua morte na revista Cromos, em 1930}

\section{Resumo}

Este artigo analisa as representações construídas, por ocasião do centenário da morte de Simón Bolívar, no número especial que a revista Cromos dedicou a essa celebração, no dia 13 de dezembro de 1930. A partir da análise de 15 textos que, em sua maioria, provêm de autores da Academia Colombiana de História, são discutidas as implicações da heroização de Bolívar para o processo de construção simbólica da nação e, mais amplamente, do continente americano, a respeito do tempo, do espaço e da população. Enfatiza-se, em particular, o papel que a Espanha e a América desempenham na representação do herói e torna-se evidente a maneira como a ovação a Bolívar constitui, por sua vez, uma ode à Espanha do ponto de vista histórico, cultural e racial, enquanto seu americanismo é ressaltado de uma perspectiva geográfica e política. Demonstra-se que a exaltação da capacidade épica do Libertador ia de mãos dadas com esforços genealógicos para evidenciar o pertencimento de Bolívar à raça branca europeia e para apresentar o processo de independência, por ele liderado, como mais uma fase da missão civilizadora que, desde a Conquista, a Espanha tinha iniciado na América. Este artigo conclui que a heroização de Bolívar levava ínsito um desprezo pelo passado pré-hispânico e um desconhecimento de toda a história anterior a 1492, bem como uma representação difamatória de seus contemporâneos. Além disso, conclui que, em harmonia com o republicanismo da revista, o Bolívar de Cromos é, em geral, um Bolívar republicano.

\section{Palavras-chave (Fonte: tesauro da Unesco)}

Simón Bolívar; Bolívar; Cromos; memória coletiva; nação; raça; identidade; representações; hispanismo. 


\section{Introducción}

Cromos nació en la tertulia de los talleres tipográficos de los socios payaneses Abelardo Arboleda y Miguel Santiago Valencia. Empezó a circular el 15 de enero de 1916, inspirada en los ideales de convivencia y progreso, propios de los años del republicanismo. En 1918, los hermanos Tamayo Álvarez compraron la revista y continuaron con la línea editorial que reunía en sus páginas a bellas mujeres junto a las élites sociales, religiosas y políticas del momento, alternando, a su vez, ensayos históricos, crónicas modernistas, poesía, novelas y cuentos de autores nacionales o traducidos. Fue una revista donde el arte y la literatura tuvieron gran importancia desde el inicio y donde la agenda de moda y belleza estuvo siempre imbricada a la de una agenda cultural más amplia, sin que por ello la política nacional e internacional pasaran desapercibidas (Vallejo, 2016a). De ahí, por ejemplo, el gran despliegue periodístico y fotográfico de la Gran Guerra, el cubrimiento de la campaña política de Enrique Olaya Herrera, a quien en tanto "encarnación del republicanismo que la publicación defendía con ahínco" le dedicara "una docena de portadas, desde su candidatura presidencial, hasta su muerte en 1938", o de la Guerra Civil Española (p. 62).

Asimismo, es notable el rol protagónico que, desde sus inicios, tuviera en sus páginas la historia nacional, o mejor, cierta representación de esta, con una decidida línea editorial en torno a conmemoraciones de próceres nacionales, fechas patrias y aniversarios del mundo cultural. Tal era la conexión de Cromos con la historia patria, que, al cumplirse veinte años de la revista, el 28 de marzo de 1936, el número correspondiente se abrió con el titular: "20 años de Cromos representan 20 años de historia nacional" (Vallejo, 2016a). El protagonismo de la literatura y de la historia patria seguiría intacto, tras la compra de la revista en 1954, por los hermanos Restrepo Suárez, propietarios de la editorial Aedita. Si bien el interés de Cromos por la historia "puede obedecer al parentesco de historiadores como Gustavo Arboleda y Joaquín Tamayo con los dueños de la revista” (Vallejo, 2016b), lo cierto es que, para el número dedicado al centenario de la muerte de Simón Bolívar, buena parte de los artículos, allí publicados, provenían de miembros de la Academia Colombiana de Historia. 
Inicialmente creada, en 1902, como Comisión de Historia y Antigüedades Patrias, esta institución, que recibe su nombre actual en 1928, surge como órgano consultivo del Gobierno para "la gestión pública de la memoria colectiva” (Castro, 2008, citado por Rodríguez, 2017, p. 3) en el contexto de un país que enfrentaba los efectos devastadores que la guerra de los Mil Días y la separación de Panamá habían dejado sobre la economía nacional y la soberanía territorial. En la construcción de un imaginario del pasado, encaminado a superar posiciones partidistas y a asentar la idea de que la paz del país se había logrado gracias a la convergencia de los dos partidos tradicionales en torno al ideal común de contribuir a encauzar el país por la senda del progreso, la Academia Colombiana de Historia desempeñaría un papel fundamental. Este imaginario, moldeado con conmemoraciones, enseñanza de la historia patria, proyectos editoriales y conservación de patrimonio histórico, recogía el espíritu de conciliación característico del movimiento político del republicanismo, cuyos años dorados coincidirían con la llamada generación del Centenario, como se denominó al conjunto de políticos, periodistas y escritores que habían alcanzado altas posiciones en la política y en letras hacia 1910, cuando se celebraba el primer Centenario de la Independencia, y la llegada a la Presidencia de la República de Carlos Eugenio Restrepo (1910-1914). Ahora bien, teniendo presente que el republicanismo surgió en un contexto favorable para el Partido Conservador, habiendo logrado instalar su visión sobre el modelo de Estado en la Constitución de 1886 — centralización política, libertades limitadas y no separación entre Iglesia y Estado- y salir victorioso de la guerra de los Mil Días, es claro que, pese a la importancia del espíritu de conciliación en el dar vida a un proyecto de patria suprapartidista, este último habría de tener una mayor impronta conservadora y que los liberales serían los llamados a hacer las mayores concesiones en torno a él, siendo la laicidad una de ellas (Arias, 2007; Ocampo, 1999). De ahí que el relato que la Academia Colombiana de Historia contribuyera a configurar, particularmente durante la Hegemonía Conservadora, cristalizara en una narrativa que reconocía a la Iglesia católica como articuladora de la historia nacional y los valores asociados a la tradición hispánica como principios constitutivos de la colombianidad; en otras palabras, en una narrativa que, en gran medida, continuaba en sintonía con el proyecto cultural y político 
de la Regeneración y asociada, por tanto, a un régimen de historicidad preocupado por la conservación del orden social (Rodríguez, 2017). A su vez, esta narrativa habría de permitir "a la república conservadora permanecer legítima para continuar la dominación desde la síntesis liberal-conservadora como fórmula de salvación" (Ayala, 2012, p. 524). Con miras a esta reinvención de la patria, que buscaba, asimismo, alejar a los colombianos del recuerdo de la tragedia y destrucción de las guerras civiles, la configuración de un panteón de héroes fue central, según Ayala. Pese a que Bolívar no se concibió a sí mismo como un héroe, ni se propuso configurar su imagen en ese sentido, tal como sus cartas a Urdaneta, O'Leary, entre otros, lo revelan (Campos, 2012), ocuparía un lugar privilegiado dentro de este panteón, de la mano de otros prohombres de la independencia. Claramente, aun cuando el panteón se recreara en el proceso de invención de una patria suprapartidista y de otros tantos proyectos a lo largo del siglo XX, en los que los valores de la independencia se usarían para legitimar posiciones a lo largo y ancho del espectro político, los procesos de heroización no eran nuevos, como plantea Ayala. Bolívar, específicamente, estaba firmemente "posicionado en el imaginario del conservatismo, desde la segunda mitad del siglo anterior. Sin excepción, todos: viejos y nuevos, lo idolatraban” (p. 535).

Precisamente, a analizar las representaciones de Bolívar en el número 741 de la revista Cromos, publicado el 13 de diciembre de 1930, voy a concentrar mi atención en este artículo. ¿Por qué Bolívar se considera un héroe? ¿Qué características se le atribuyen? ¿Qué rol ocupan España y América en la identidad del héroe? ¿Qué implicaciones tiene la representación de Bolívar en la imaginación del continente americano y de las naciones hispanoamericanas desde el punto de vista del tiempo, el espacio y la población? ¿En qué sentido la heroización de Bolívar supone una oda a la madre patria y a su vez una oda a la independencia y al proceso de construcción republicano que esta desencadena? ¿De qué manera la representación de Bolívar legitimaba el proyecto político del republicanismo que la revista defendía? ¿De qué manera cooperaba la representación de Bolívar en Cromos con el régimen de historicidad construido por la Academia Colombiana de Historia, es decir, con un régimen de historicidad preocupado por la conservación del orden social? 
Cabe destacar que, salvo el trabajo de Ayala (2012) sobre el papel que la representación de Bolívar desempeñara en el moldeamiento identitario del fascismo colombiano, no hay trabajos que ofrezcan, más allá de abordajes generales y diacrónicos sobre las imágenes de Bolívar y Francisco de Paula Santander en la lucha partidista colombiana (Melo, 2012), por lo demás necesarios y pertinentes, lecturas encaminadas a dar cuenta de la manera como las representaciones, en este caso sobre Bolívar, cristalizaron en las fuentes mismas. Este artículo es un aporte en este sentido.

\section{Metodología}

En este artículo, analizo las representaciones que sobre Bolívar se construyen en el número 741 de la revista Cromos, que contiene alrededor de veinte textos, entre ensayos, crónicas, noticias y poemas, todos dedicados a celebrar el centenario de la muerte del Libertador. Sin embargo, me baso en quince textos, y dejo de lado cinco, ${ }^{2}$ dedicados a describir literalmente la muerte de Bolívar y la casa donde fallece, sin ofrecer posibilidad alguna al análisis y la interpretación histórica en torno a las preguntas planteadas.

La mayor parte de los textos, publicados en este número y aquí analizados, provienen de miembros de la Academia Colombiana de Historia; es el caso de Luis Augusto Cuervo (1893-1954), entonces presidente; José Alejandro Bermúdez (1886-1938), vicepresidente; Jesús María Henao (18701944) y Gerardo Arrubla (1872-1946), autores de dos de los textos más emblemáticos de la historia del país, publicados para conmemorar el primer Centenario de la Independencia, a saber, Historia de Colombia para la enseñanza secundaria y el Compendio de la Historia de Colombia para la enseñanza en las escuelas primarias de la República; y Enrique Otero D'Costa (1883-1964) y Miguel Aguilera (1895-1973). Todos, salvo este último, pertenecen a la primera generación de la Academia Colombiana de Historia, muy activa durante la Hegemonía Conservadora. Por su parte, Aguilera forma parte de la segunda generación, particularmente importante en la década de 1950, en el proceso de restauración conservadora en el que Cuervo, nuevamente, volvería a destacarse (Rodríguez, 2017). Otro de los

2 “En San Pedro Alejandrino”, de José María Rojas Garrido; “San Pedro Alejandrino”, de José Ignacio Méndez; “Enfermedad y muerte de Bolívar”, de Jorge Mercado; “La muerte del cóndor”, de Jesús Henao y Gerardo Arrubla. 
textos del corpus es de autoría de Eduardo Castillo (1889-1938), entonces miembro de la Academia de la Lengua y dos más provienen de autores colombianos contemporáneos, a saber, Cornelio Hispano (1880-1962) y Simón Latino (1898-1987). Un texto es de un autor venezolano contemporáneo, Eduardo Picón Lares (1899-1960). Dos son de autores españoles: uno contemporáneo, como es el caso de José María Salaverría (1873-1940), y otro, Félix Soublette (1840-1899), fallecido en las postrimerías del siglo XIX. Salvo Simón Latino, todos los autores colombianos del siglo XX son de tendencia conservadora; por su parte, hay una contribución de un autor liberal ecuatoriano, Juan Montalvo (1832-1889), y otra del liberal colombiano José María Garrido (1824-1883), que, sin embargo, no tomo en cuenta para el análisis, por la razón mencionada.

\section{Bolívar: un grande entre los grandes}

Bolívar se presenta como la figura central de la emancipación americana y como tal aparece ovacionado no solo como un héroe de talla continental sino universal. No como uno más entre los grandes, sino como el más grande de la historia; superior a todos los grandes políticos y guerreros del mundo antiguo y moderno. Bolívar es incluso reverenciado como un semidiós. Las explicaciones dadas para dar cuenta de la grandeza de Bolívar a nivel universal llevan ínsitas descalificaciones de sus contemporáneos, especialmente de los sectores subalternos que componían el grueso del Ejército libertador. Cuanto más se elevaba Bolívar, más bajo caían sus contemporáneos, concebidos, no como facilitadores, sino como obstáculo a superar para llevar a cabo la gesta emancipadora. A su vez, estas explicaciones llevan ínsitas representaciones del espacio y del tiempo del continente americano y, de manera concomitante, de las naciones hispanoamericanas.

De hecho, la exaltación de la figura de Bolívar va de la mano de una reconstrucción hispanista del pasado nacional; si la historia comienza con el Descubrimiento y con la Conquista, encuentra en la revolución de la Independencia su siguiente hito fundamental. Más aún, conquista y revolución aparecen indisolublemente ligadas, porque la segunda está llamada a continuar lo que tres siglos atrás la Conquista había desencadenado, a saber, el proceso civilizatorio en América. Si bien esta relación de 
continuidad implicaba pasar de largo sobre tres siglos de historia colonial, salvo alguna referencia negativa al colonialismo español, la crítica es conspicua por su ausencia. Claramente, para los autores de este número especial de Cromos, en el legado español (lengua, raza y religión), las repúblicas hispanoamericanas encontraban su identidad cultural. Marcar el inicio de la historia hispanoamericana con la llegada de Colón suponía, cuando menos, un desprecio por el pasado prehispánico y un claro desconocimiento de este como parte integral de la historia de las repúblicas, cuyo origen Bolívar había posibilitado.

Ahora bien, si, por una parte, hay un claro esfuerzo por vincular la gesta emancipadora a la ascendencia española de Bolívar, estableciendo de esta manera una relación de continuidad entre conquista y revolución, por otra, también es ostensible, en las fuentes, un claro esfuerzo por esencializar la lucha bolivariana en la geografía americana. América no es solo el lugar de nacimiento de Bolívar o el teatro de su acción, es, a su vez, un actor con múltiples valencias. Sirve como signo de la predestinación revolucionaria de Bolívar; su estado salvaje da cuenta de la capacidad de este para subyugarla. A su vez, su majestuosidad es un signo mismo de la grandeza del prócer, en el que lo único propiamente americano parece ser la geografía. Dicho de otra manera, en un mundo de naturaleza, sin cultura y sin historia, más allá de aquella iniciada por los españoles en 1492 (Pratt, 1992), lo único que parecía estar a la altura de Bolívar era la naturaleza.

El dramaturgo y poeta español Félix Soublette, fallecido en Caracas en 1899, autor de dramas históricos como Miranda, premiado con medalla de plata en Panamá en el certamen con motivo del centenario del nacimiento del Libertador en 1883 por su obra en prosa Paralelos, y con medalla de oro, por parte de la Academia Venezolana de la Lengua, en 1892 por su poema épico Batalla de Ayacucho, a propósito de la conmemoración del centenario del nacimiento del mariscal Antonio José de Sucre, en "Bolívar" se embarca en la tarea de comparar a este gran hombre con otros grandes de la historia, para hacer énfasis en dos aspectos fundamentales. Por un lado, Soublette resalta el hecho de que nunca un hombre hubiera hecho tanto con tan poco. Mientras que Alejandro, héroe macedonio, había sido un rey, obede- 
cido por Grecia y su pueblo; mientras "El africano, hijo del grande Amílcar [... ] regía un poderoso ejército"; mientras César lideraba regiones romanas y Napoleón combatía ejércitos franceses; Bolívar "de la nada lo hizo todo". Por eso era grande, inmenso. En otras palabras, mientras grandes hombres de la historia se habían destacado por su liderazgo frente a otros hombres, Bolívar se erigía por encima de todos ellos, porque el grueso de la población de la que se componían sus filas valía muy poco. Por contraste, claramente inferimos que sus filas se componían de pseudohombres u hombres a medio civilizar. Soublette concreta, entonces, la idea de grandeza de Bolívar a partir de la deshumanización de sus tropas, por su puesto, hechas de la misma materia del pueblo bajo de las colonias o del pueblo de las futuras naciones hispanoamericanas.

Además, continúa Soublette, para llevar a cabo su empresa, Bolívar tuvo que luchar contra el fanatismo, la ignorancia y los hábitos de vasallaje y sumisión que, arraigados durante "300 años de esclavitud”, habían dejado una honda impronta en las costumbres públicas y privadas. Asimismo, tuvo que luchar contra una suerte de "India oriental, inmóvil en su abyección, dividida en castas"; es decir, contra una sociedad colonial, fuertemente jerarquizada, que el francés decidiera representar apelando a un tono orientalista tan propio de buena parte del pensamiento europeo del siglo XVIII y XIX. De donde, si la representación de Bolívar que hiciera Soublette está aunada a una representación negativa de la población (de la que provenía el Ejército libertador), está también aunada a una representación negativa de la sociedad, en general, y de su historia, reducida a su pasado colonial.

De manera semejante, la heroización de Bolívar suponía una construcción del espacio, teatro de su acción. En efecto, la grandeza de Bolívar se derivaba del hecho de haber tenido que enfrentarse a una naturaleza, "casi en estado primitivo", malsana, con soles abrasadores, que desencadenaban fiebres que enloquecían. La geografía americana se representaba, entonces, a partir de la reproducción de viejas tesis buffonianas y de otros autores de la Ilustración europea, reafirmadas a su vez por autores criollos del siglo XIX (Nieto, 2006), según las que la naturaleza en el Nuevo Mundo fungía como una fuerza antagónica a la civilización. Claramente, cuanto más salvaje y 
en estado bruto la naturaleza se presentara, más superlativas resultaban las virtudes del hombre capaz de someterla. Además, Bolívar, de acuerdo con Soublette, tuvo que enfrentar la opinión pública realista y el "fuerte y poderoso [... español, inspirado en el denuedo y tenacidad indomables de su raza”. De ahí que, al hilo de su interpretación, Bolívar se creciera en su estatura de héroe, por un lado, comandando hombres americanos, cuyo valor racial, inferimos, no solo es de escaso valor, sino ciertamente inferior al de su adversario español, además de tener que enfrentar dificultades de tipo histórico (el legado colonial español) y geográfico (la naturaleza americana aún en mora de ser subyugada por la mano civilizadora).

La imagen de Bolívar habiendo formado de la nada un ejército había entrado ya en los anales de la historia, con la publicación, en 1827, de la Historia de la Revolución, de José Manuel Restrepo; un texto reeditado, a su vez, en 1858 (Melo, 2012). Esta misma imagen la encontramos en un texto publicado en el Papel Periódico Ilustrado (1881-1888), ampliamente reconocido, no solo como una de las publicaciones periódicas más importantes de la segunda mitad del siglo XIX en Colombia, sino por haber desempeñado un papel central en la consolidación del proyecto nacional de corte católico, hispánico y centralista, propio de la Regeneración (Jiménez, 2012). Precisamente, en la celebración del centenario del nacimiento de Bolívar, en 1783, en el número especial que a este propósito el periódico de Alberto Urdaneta dedicara, encontramos un texto de Manuel Briceño, "La campaña de Boyacá: fragmento de un tratado sobre estrategia”, con este mismo argumento. De acuerdo con Briceño, comparando los medios a su disposición y los obstáculos a superar resultaba claro que "el plan de BOLÍVAR está por encima de todas las reglas del arte, no ha tenido ejemplo en la antigüedad y de seguro no tendrá imitadores en el porvenir" (Papel Periódico Ilustrado, 1783, p. 382). Bolívar había logrado mucho, con muy poco, habiendo tenido que vencer obstáculos tanto de orden geográfico como humano. Por un lado, se había enfrentado a "la fría y elevada cordillera de los Andes, atravesada apenas por malos caminos de herradura, sembrados de obstáculos", y a las pampas del Apure y del Arauca, con zonas amplias pantanosas, producidas por el desborde de los ríos; por otro, a la dificultad de comandar "llaneros acostumbrados á vivir en un clima ardiente", bárbaros 
sin vestido, gentes a medio civilizar, que luchan contra enemigos equipados, liderados "por jefes y oficiales valerosos y entendidos". En este sentido, la campaña de Boyacá había sido superior incluso "á la de Aníbal sobre el centro de la Italia [... ] y á la de Napoleón sobre el mismo teatro” (Papel Periódico Ilustrado, 1883, pp. 382-386).

Ahora bien, si, por un lado, Soublette construye la grandeza de Bolívar resaltando las múltiples dificultades que enfrentó, por otro, hace hincapié en su heroicidad y destaca la bondad de los principios que inspiraban su acción, en contraposición al egoísmo y a los intereses personales que habrían guiado a otros grandes de la historia. Así, mientras "el juramento de Aníbal [en Cartago] es un grito de rencor, la llama del odio; el juramento de Bolívar [en el Aventino donde prometió liberar a las naciones hispanoamericanas] es un himno de amor, el reflejo de la gloria”. En Soublette, y demás autores que participan en este número especial de Cromos, se percibe la impronta duradera que sobre la escritura de la Independencia de Colombia, y demás países hispanoamericanos, tendría, durante buena parte del siglo XX, la obra del escritor británico Thomas Carlyle (1795-1881), con su visión de la historia universal como producto de la gesta de grandes hombres, concebidos a su vez como paradigma de virtudes a imitar por la sociedad (Campos, 2012). Precisamente, en la heroización de Bolívar, desde la esfera exclusiva de sus costumbres y valores, entre las que destacan su capacidad de amar, humanidad, sobriedad y discreción, van a insistir los artículos del editor y librero colombiano Simón Latino (1898-1987) ("Bolívar y las mujeres: un amor ignorado"), de Miguel Aguilera ("La leyenda negra sobre la crueldad de Bolívar”), del diplomático y periodista venezolano Eduardo Picón Lares (1899-1960) ("La sobriedad del Libertador") y un texto sin firma ("Fanny Dervieu du Villars y su hijo Augusto").

En la imagen de Bolívar, que se eleva por encima de todos los demás héroes de la historia, en tanto instrumento divino y habiendo logrado tanto con tan poco, va a ahondar otro de los textos publicados en este especial de Cromos, a saber, "Bolívar”, texto del poeta colombiano Ismael López, más conocido como Cornelio Hispano (1880-1962), quien en 1912 publicara Diario de Bucaramanga: vida pública y privada del libertador Simón Bolivar, 
diario del general francés Louis P. de la Croix sobre la vida del libertador durante su estancia en la villa de Bucaramanga entre abril y junio de 1828, momento en el que se llevaban a cabo las deliberaciones en la Convención de Ocaña (Ojeda, 2008); en 1925, El libro de oro de Bolivar y, con ocasión del centenario, Los cantores de Bolivar. El texto suyo que aquí nos compete es un monólogo a Bolívar. Para referirse a él, Hispano recurre, por un lado, a la obra del escritor británico mencionado. De ahí que afirmara: "[Eras] de esa estirpe de quienes dijo Carlyle que son la sal de la tierra": "Tus ojos eran fecundos y serenos como los de un dios!"; "eras uno de esos enviados de lo Eterno, cuya presencia coincide con determinadas épocas de la evolución universal, y sólo así comprendemos [...] que un solo hombre haya marcado en su tiempo impresión tan profunda que aún se advierta, por sus beneficios, en las generaciones sucesivas y remotas". Por otro, apela a la imagen de Bolívar como un héroe superior a todos los que lo precedieron, en la medida en que enfrentó dificultades, sin precedente alguno en la historia. Bolívar había sido un "sol, un numen", cuya grandeza hacía opacar la de otros héroes del mundo antiguo y moderno, por las dificultades superadas, entre ellas, haber liderado "rudos y casi salvajes llaneros". "Igualaste o sobrepujaste en talento creador y arrebatadora elocuencia a cuanto más elevado había sido o era en tu tiempo: [... ] pero en Boyacá fuiste más grande que Aníbal por haber rendido más grandes obstáculos”.

El esfuerzo por resaltar la universalidad del héroe corre paralelo al esfuerzo de Hispano por resaltar su hispanidad, desde el punto de vista racial y cultural. Si la gesta de Bolívar fue posible gracias a que Dios lo eligiera como emisario, también lo fue gracias al estímulo que la raza española, de cuño vasco, le imprimiera a sus acciones. Haciendo explícito hincapié en la raza como causa explicativa del éxito de Bolívar, Hispano sostiene:

Pero, [i] en qué fuerzas misteriosas [...] de qué jugos se nutrió la planta que te dio vida, oh flor maravillosa de tu raza! [...] Nosotros sólo sabemos que fuiste un resumen y expresión de todas las virtudes acumuladas por los siglos en una familia de la especie humana, cuyas raíces aún hoy se muestran entre las grietas de las abruptas rocas cantábricas. Ese pueblo es el vasco [...] [i]Tal es la raza donde te nutriste, árbol de oro! Allá está tu fisionomía moral, la imagen de tu conciencia, el espejo de tu espíritu. 
Para exaltar la figura de Bolívar a partir de la comparación con grandes hombres de la Antigüedad, el ensayista y novelista ecuatoriano, de tendencia liberal y anticlerical, Juan Montalvo (1832-1889), no solo evoca el carácter providencial del Libertador ("hijo de la luz, su progenitora es divina”), sino que sostiene que la única variable que podría aminorar su brillo sería el tiempo. Frente a genios del despotismo como Luis XIV, genios de la ambición como Napoleón o genios civilizadores como Pedro I de Rusia, "el genio de la libertad en ninguna parte ha de ser inferior".

\begin{abstract}
¿En qué cede a los grandes hombres de lo antiguo? En que es menor con veinte siglos, y sólo el tiempo, viejo prodigioso, destila en su laboratorio mágico el óleo con que unge a los príncipes de naturaleza. ¿Qué será Bolívar cuando sus hazañas, pasando de gente en gente, autorizadas con el prestigio de los siglos, lleguen a los que han de vivir de aquí a mil años? Podrá Europa injusta y egoísta, apocarnos cuanto quiera ahora que estamos dando nuestros primeros pasos en el mundo: pero si de ella es el pasado, el porvenir es de América, iy las ruinas no tienen sonrisas de desdén para la gloria!
\end{abstract}

Casi como términos intercambiables aparecen Bolívar y América en esta cita, enmarcada en el contexto de una interpretación que da cuenta del longevo esfuerzo, propio del pensamiento criollo decimonónico, por intentar refutar las tesis europeas sobre la presunta inferioridad americana (Nieto, 2006), particularmente aquellas asentadas con el movimiento de la Ilustración (Gerbi, 1973). Así como para América, un continente joven y sin historia, llegaría el día de estar a la altura cultural de Europa e incluso de sobrepasarla ("si de ella es el pasado, el provenir es de América, y las ruinas no tienen sonrisas de desdén para la gloria”), también para Bolívar llegaría el día en que el panteón de héroes del Viejo Mundo ya no pudiera hacer sombra alguna a su brillo. Si a mediados del siglo XIX, cuando Montalvo escribía, el brillo de los héroes de Europa se acentuaba por el peso que la historia de la civilización les confería, en el futuro, cuando el Nuevo Mundo sobrepasara la gloria del Viejo Mundo, el brillo de Bolívar, amparado por la fuerza de la civilización americana, no habría de tener rival alguno. $\mathrm{Si}$, por un lado, Montalvo resaltaba el carácter americano de Bolívar, por otro, destacaba su ethos revolucionario no solo como expresión de la Providencia, sino también como una fuerza gestada en 
virtud de su pertenencia a la cultura española y más ampliamente a la civilización occidental. Leyendo teleológicamente la obra de Bolívar, con la revolución como telos, y apelando a la figura de la espada como clara metonimia de la gesta independentista, Montalvo relaciona la espada de Bolívar con la de otros defensores modernos de la emancipación. Concibe a estos últimos como emisarios divinos y herederos de una espada primigenia, a saber, la del primer monarca del reino de Asturias, Pelayo, reconocido por haber contenido la expansión mora, en la península ibérica, e iniciado la mal llamada Reconquista. En palabras de Montalvo: "la espada de la libertad, esa hoja grande que empuñó Pelayo y que, depositada en las regiones secretas e invisibles de la Providencia, ha ido sirviendo a los bienhechores de los pueblos, a Guillermo Tell, a Washington, a Bolívar”. Por medio de la conexión entre la Reconquista mora, que concluye con la toma de Granada el mismo año del Descubrimiento de América, y la Independencia hispanoamericana, Montalvo vincula dos eventos profundamente asociados, implícita o explícitamente en la narrativa que moviliza Cromos en torno al centenario de la muerte de Bolívar, a saber, por un lado, el Descubrimiento y la Conquista de América, por otro, la Independencia.

La exaltación de Bolívar en una reconstrucción hispanista del pasado nacional y continental, con estos dos hechos indisolublemente ligados y presentados como triunfo de la raza española, es ostensible, con toda claridad, en "La juventud de Bolívar: Los padres del libertador: Don Juan Vicente Bolívar y Ponte. Doña María de la Concepción Palacios y Blanco”, texto de Luis Augusto Cuervo, entonces presidente de la Academia Colombiana de Historia y uno de los académicos más influyentes en la dirección del que fuera la caja de resonancia fundamental de los planteamientos de sus miembros, a saber, el Boletín de Historia y Antigüedades, publicación de cuya edición y difusión se encargó por diecisiete años (Rodríguez, 2017). Haciendo eco de la idea de Bolívar como grande entre los grandes, Cuervo comienza su artículo recurriendo a una gesta de glorificación ficticia en la que los letrados de todas las edades le brindan honores al Libertador, para continuar con una lectura teleológica de su vida, en la que geografía, raza y cultura intervienen para señalar, desde el día de su nacimiento, en 1783, el camino de la revolución. Si la ascendencia española de Bolívar, marcada 
desde el punto de vista de la raza y de los referentes culturales, habría de configurar el impulso posibilitador de la gesta revolucionaria, la geografía americana también cumpliría un papel esencial en esta empresa. Más que como lugar de nacimiento y mero teatro de acción, se construye en un espacio ontológicamente ligado a la revolución. La geografía americana, representada con múltiples actores (la tierra, la cordillera andina, el Tequendama, el Iguazú, los vientos del cerro de Ávila), adquiere vida y sentido en cuanto teatro de la acción revolucionaria. "A la sombra [... ] Dos blasones, el de la Patria y el de la estirpe [... ] nació Simón Bolívar". Si en su casa el escudo de los Bolívar de Vizcaya atestiguaba el abolengo de la familia, casi cuarenta años antes de la revolución de la independencia, banderas de esta revolución e insignias de la república ondeaban ya; junto a ellas, el cóndor de los Andes habría de posarse, después de la victoria de Ayacucho. Así como su madre presentía en sueños que uno de sus hijos sería colmado de la mayor gloria e ingratitud, "la tierra americana $[. .$.$] llevaba en sus entrañas los mis-$ mos presentimientos $[\ldots]$ de la mujer excelsa que acababa de dar al mundo un genio". Por eso, cuando Bolívar nació, la tierra "vibró y se conmovió al sentir sobre sus lomos un chiquillo portentoso". La tierra americana se convirtió ella misma en portavoz revolucionaria. Los más altos picos de la cordillera andina "lanzaron oriflamas de fuego y humo como faros de entusiasmo en la suave quietud colonial", mientras que a los pueblos gritaba el Tequendama, en el norte, y el Iguazú, en el sur, "que acababa de iniciarse una nueva era en su historia política". Ahora bien, este grito que anticipaba la emancipación americana no era un grito de ruptura con España, sino uno encaminado a homenajearla, enlazando los dos acontecimientos más importantes de la historia de América, a saber, conquista y revolución, como triunfos de la raza española. El mar de Atlante "encrespó sus olas" y hasta "las heroicas costas de Palos de Moguer llegó el eco de este nuevo grito, glorioso también por ser un triunfo de la raza, así como tres centurias antes llegaba hasta sus dársenas [... ] la prolongación de la victoria definitiva consagrada por el Almirante de Castilla [... en la ronca voz de Rodrigo de Triana [las cursivas son mías]”.

Si el Tequendama e Iguazú habían hecho lo suyo, los vientos del cerro de Ávila que custodia a Caracas "le murmuraban" al pequeño niño el 
anhelo de ser libres. Hilando una cadena de hechos, que solo anacrónicamente y con poco rigor en el manejo de las fuentes podría entenderse así, Cuervo sostiene que al niño Bolívar llegaron ruidos de los perseguidos guerreros de Mérida y del Socorro, como preparándolo para la "gigantesca empresa que pondría su nombre más allá de los tiempos”.

Por otra parte, si los enciclopedistas franceses moldearon su cabeza con ideas sobre el progreso humano, su madre le inculcó nociones de hidalguía y valores propios de la templanza vasca. Cuervo resalta el hogar caraqueño como un bastión de conocimiento, virtud y religiosidad, que recoge escenas de las celebraciones del santo del pequeño y de su primera comunión. Aprovechaba, a su vez, para resaltar que, desde niño, Bolívar, armaba con soldados de plomo "pequeña[s] lucha[s] entre esclavos y libertadores". Cuervo promueve la identidad de Bolívar, desde el punto de vista racial y cultural, asociada a España, y destaca a esta última como la fuente primordial de su impulso revolucionario. Por eso, como mencionábamos antes, concibe la emancipación americana como "un nuevo grito, glorioso también por ser un triunfo de la raza”. A su vez, Cuervo esencializa el ethos revolucionario de Bolívar, evidente desde la más temprana infancia, en el entorno natural. De ahí que, si España le habla a Bolívar desde la raza y la cultura, posibilitadoras ambas de la gesta independentista, América lo hace desde la geografía. Todo junto, contexto cultural, sangre y naturaleza, presagian la grandeza revolucionaria de Bolívar.

Cuervo hace hincapié en la elegancia del hogar en el que Bolívar creciera, rodeado de "salones tapizados de damasco rojo" y pletórico de referencias de la cultura peninsular y occidental. Por ejemplo, entre los libros, se destacaba un ejemplar, valioso por la antigüedad de la edición, pero sobre todo porque proporcionaba un antecedente, una metáfora, por lo demás recurrente en los textos de la época, de lo que vendría a ser la obra de Bolívar. Se trataba de un ejemplar de El Quijote, editado por Juan de la Cuesta en 1608. Las aventuras del Quijote anticipaban las correrías de Bolívar por liberar cinco naciones, subir al Chimborazo, extendiendo lazos de unión y fraternidad, desde el Orinoco hasta el río de la Plata. Asimismo, eran notables los retratos de antepasados que adornaban las paredes. En ellos damas 
cuyas "manos, blancas y transparentes $[. .$.$] alargadas por el pincel de algún$ discípulo del Greco, parecen hechas para acariciar rosas madrileñas y olorosos jazmines de Sevilla"; hombres con armaduras que dan cuenta de luchas pasadas. Todos los antepasados "sonríen a la casta" y dan cuenta de las épocas cuando "los de su sangre" fundaban en Vizcaya el caserío de Bolívar: "Gentes de pesca [...] esos hombres en el correr silencioso de los siglos, preparaban la raza [las cursivas son mías] para que ella fuera robusta y firme el día de la culminación de sus esfuerzos en el nacimiento del Libertador de América”.

A reforzar la relación entre el Libertador y España, concretamente entre la conquista y la revolución, contribuiría, en el relato de Cuervo, "la daga del conquistador Simón Bolívar, el viejo [... templada en puro acero toledano" y colgada en uno de los corredores de la mansión. En este mismo sentido, contribuían las enseñas españolas, con escudos bordados de amarillo y rojo, concebidos para exaltar la grandeza de la monarquía "en todo el azul del cielo americano”. En esos colores, afirma Cuervo, se percibía ya la transición hacia el pabellón que sobre el palo más alto del Leandro izara Miranda como muestra de su patriotismo. Precisamente, la bandera de color amarillo, azul y rojo que izara Miranda, el 12 de marzo de 1806, en el Leandro, tras la frustrada invasión a Coro, en Venezuela, daría lugar, posteriormente, a la bandera de la Gran Colombia. En definitiva, la prosa poética y la ficción, recursos empleados, ambos, en este texto, son funcionales para no hacer de la gesta revolucionaria y de la independencia americana un momento de ruptura con España, sino más bien el inicio de una nueva fase en la que esta última estaba llamada a seguir presente, ya no desde el punto de vista político, sino desde una perspectiva racial y cultural.

La tendencia a inscribir la predestinación revolucionaria de Bolívar tanto en su biografía como en la geografía americana es visible también en el texto “La Quinta de Bolívar”, del sacerdote José Alejandro Bermúdez, entonces vicepresidente de la Academia Colombiana de Historia y autor de una guía sintética para ayudar a los estudiantes universitarios a preparar sus exámenes (1927) y del Compendio de la Historia de Colombia (1931), reeditado hasta bien entrada la década de 1950. En el texto que publica para Cro- 
mos, el sacerdote recoge la vida del Libertador a partir del significado que en ella tendrían tres casas, a saber, su casa natal, la casa que da lugar al título del artículo y la quinta de San Pedro Alejandrino donde fallecería. Particularmente importante para el propósito de Bermúdez sería la casa natal de Bolívar, enmarcada en la ciudad costera de Caracas. "La casa natal [... ] nos trae a la mente la infancia del Libertador y el recuerdo de aquellas empresas guerreras con que dio comienzo a su obra emancipadora de América. Caracas $[\ldots]$ una ciudad costanera abierta a todo viento de renovación y revuelta. Bolívar y Miranda tenían que nacer aquí”.

Si no como presagio de la revolución, sí como metáfora de la grandeza del héroe, el recurso de la geografía americana está también presente en el poema "Bolívar”, de Enrique Bonilla Álvarez (1848-1913), oriundo de Tunja, y quien, tras el fallecimiento de Rufino Cuervo, fuera elegido para ocupar su silla en la Academia Colombiana de la Lengua. En cada una de las tres estrofas del poema, el Chimborazo, el Tequendama y el Océano evocan la grandeza del Libertador.

Por otra parte, "Colón y Bolívar" implica una clara reconstrucción hispanista de la historia. Se trata de un texto de Jesús María Henao, quien, además de ser coautor de los textos emblemáticos de historia, ya mencionados, había publicado, con ocasión del centenario de la muerte del Libertador, una nueva síntesis histórica, pletórica de ilustraciones, con Bolívar como protagonista, a saber, La grandeza de Bolivar (1930). En la oda simultánea a Colón y Bolívar, publicada en Cromos, "El descubrimiento de América y su emancipación, figuran entre los mayores sucesos de la Historia $[. .$.$] aquel$ 12 de octubre de 1492, fecha perdurable y de abrazo eterno de dos mundos [... ] seguirá con el desarrollo o desenvolvimiento del inmenso porvenir de América [... Colón y Bolívar son héroes de un destino manifiesto: se agitaron grandemente y Dios los condujo [las cursivas son mías]”. Henao exalta los dos momentos fundacionales de la historia del Nuevo Mundo y se propone trazar la genealogía de una denominación, capaz de honrar verdaderamente la memoria del descubridor, a saber, Colombia. De ahí que en ese continuo teleológico del que Colón y Bolívar son sus mayores exponentes, recupere los nombres de Bartolomé de las Casas y Francisco Miranda. 
En efecto, sostiene Henao, el primero en erigirse en contra de la injusticia de que el continente descubierto por Colón se llamara América había sido Bartolomé de las Casas, quien manifestó, en su Historia general de las Indias (1552-1559), que el continente debería haberse llamado Columba. En el sentido de esta reivindicación lo sucedió Francisco Miranda, "aquel soldado $[. .$.$] que por sus distinguidos servicios en su carrera tan señalada ha$ sido mirado como el precursor de la independencia de la América española". Como "concilio colombiano" había concebido Miranda la constitución de un gobierno con un cuerpo legislativo, facultado para otorgar leyes en toda la federación americana, y con un poder ejecutivo asentado en Panamá, con Colón como capital. A De las Casas y Miranda los sucedió Bolívar, creador de la República de Colombia. Y si la Gran Colombia desaparecería casi al tiempo que Bolívar, Henao destacaba que a remediar la injusticia cometida contra Colón vendría la Nueva Granada, que llevaría por un cuarto de siglo, desde la Constitución de Rionegro, el nombre de los Estados Unidos de Colombia y, posteriormente, con la Constitución de 1886, la República de Colombia.

El último texto a considerar en esta sección es interesante porque se aleja del paradigma representacional hasta aquí evidenciado. Es decir, Bolívar no es representado como un español, blanco o como un hombre que adquiera la posición de héroe en virtud de su superioridad y distancia frente al ejército que lideraba. Se aleja aún más del paradigma, porque la construcción de Bolívar que ofrece no es producto de la mente de los intelectuales a los que este número especial de Cromos convoca, si bien sí requiere su mediación para visibilizarse en la revista. Se trata del "Galerón del zambo Golíbar”, un texto en el que Enrique Otero D’Costa transcribe coplas de llaneros que dan cuenta de la percepción de estos sobre Bolívar. Bolívar es Golíbar. No es blanco, es de color canela y zambo; categoría racial que aquí se acuña positivamente y denota cercanía entre los llaneros y Bolívar, pero que, en el imaginario criollo letrado, tradicional, señalaba la que se consideraba como la peor mezcla racial de todas, a saber, la de negro con indio. Lejos de indicar conexión identitaria alguna entre Bolívar y España, se resalta lo contrario. No es español; es un zambito enfrentado a los godos. Probablemente, la experiencia de Otero D’Costa en las regiones, 
quien gestionó centros de historia de la Academia Colombiana de Historia (Rodríguez, 2017), contribuyera a posibilitar este tipo de registros. Además de rivalizar con la imagen hegemónica de Bolívar, la imagen popular, que este texto ofrece, nos permite inferir cuán vivo estaba el recuerdo del Libertador en sectores subalternos de la sociedad, pues las coplas que Otero recoge las escucha cantar en pleno siglo XX. En la voz de los llaneros:

Arriba zambos der yano

A los der brazo arremangao,

Que'l Libertao'nos yeva

A peliar como es mandao

Que Golíbar es nombrao...

Zambito color canela,

El zambo más requintao

Más caliente quiún ají

O quiún toro encalambrao

Cuando va tras de los godos

A batirles el cacao

¿Qué nos plantea, entonces, la representación hegemónica de Bolívar en Cromos? ¿Qué relación tiene con el tiempo presente en el que el número especial se publicó y circuló? ¿En qué medida las características atribuidas al héroe y los motivos conferidos para convertirlo en tal hacían eco de debates y problemas contemporáneos en Colombia? Si el "héroe [es un] modelo de virtudes y valores, de gran potencial estratégico para la formación del ciudadano miembro de una comunidad política y partícipe del fortalecimiento de la república” (Jiménez, 2002, p. 128), ¿̇cómo se comprendía el fortalecimiento de esta última? Salvo por la incursión de "Golíbar", el Bolívar de Cromos es español, blanco, con fuertes conexiones con una cultura hispana y católica; más aún, sus capacidades de semidiós, de enviado divino, provienen, en buena medida, de la susodicha composición racial, claramente distinta y superior a la del pueblo que, entonces, componía sus ejércitos. Bolívar es grande porque sus contemporáneos no eran nada; por eso, la gesta emancipadora emana, sobre todo, de su fuerza creadora. Bolívar es grande porque logró subyugar a la naturaleza, lo único que en el Nue- 
vo Mundo estaba a su altura; es grande porque, con la independencia y el proyecto republicano, logró continuar con el proceso de civilización que había dado origen a la historia del continente de la mano de Colón y los conquistadores españoles.

En la narrativa de Cromos, hay un claro eco de un debate contemporáneo, que capturó la atención de la élite colombiana, preocupada por enrutar al país por la vía del progreso. Entre el 21 de mayo y el 23 de julio de 1920, prestigiosos intelectuales y médicos del país se reunieron en el Teatro Municipal de Bogotá para discutir sobre los factores de un fenómeno, ante sus ojos, indiscutible, a saber, la presunta degeneración de la raza colombiana (Muñoz, 2011). Las memorias del evento se publicaron el 12 de octubre de 1920 en un libro titulado Los problemas de la raza en Colombia. Geografía, cultura y biología aparecen allí como las explicaciones más recurrentes para dar cuenta del problema, con las consiguientes medidas a tomar para solventarlo: desde el fomento de inmigración extranjera para promover el blanqueamiento de la sociedad, donde se percibía el mestizaje como un proceso de degeneración física y moral, hasta la implementación de políticas de higiene y educación, para corregir la degeneración por la vía de la cultura y no de la biología. Independiente de la perspectiva asumida, el consenso residía en la percepción de la población colombiana como problema y rémora del progreso. Es inevitable pensar en una clara relación entre esta discusión y el número de Cromos que nos convoca. Bolívar y los intelectuales del siglo XX, abocados a estimular el progreso en una sociedad no preparada para ello. Por otra parte, el que una discusión como la del Teatro Municipal o la confección de un número conmemorativo como el de Cromos tuvieran lugar en el contexto de una época, hondamente marcada por fuertes conflictos sociales, no deja de llamar la atención sobre el esfuerzo de las élites por deformar en la representación o silenciar lo que, por el contrario, estaba de manifiesto, a saber, la agencia y movilización de los actores subalternos. De la mano del desarrollo industrial que el país comenzaba a vivir en los primeros años del siglo XX, múltiples acciones de obreros y campesinos, como huelgas, invasiones de tierra, prensa popular, sindicalización y alianzas con el partido socialista recientemente formado, "dejaron al descubierto que las masas se estaban despertando y aspiraban a 
una mayor autonomía” (Arias, 2007, p. 19). No obstante, arguyendo que tras el malestar popular se ocultaban peligrosos intereses comunistas que ponían en riesgo valores esenciales de la nación, la reacción de la dirigencia nacional fue, por lo general, represiva (Arias, 2007). Silenciar o deformar en el pasado para contribuir al mantenimiento del orden social en el presente. En eso, quizá, consista el régimen de historicidad o, en otras palabras, la relación entre pasado y presente, propuesta por la revista Cromos.

\section{Rehusar a ceñirse la corona: Bolívar republicano}

Si en la celebración del centenario de su muerte los liberales insistirían en la dominación injusta que Bolívar destruyó, los conservadores, que no lograron festejar la efeméride desde el Gobierno, se concentrarían en exaltar al hombre pletórico de valores heroicos (Ayala, 2012). En ese sentido, la narrativa de Cromos estaría más cercana a la del discurso conservador en tanto resaltaría más al héroe y mártir que a la injusta dominación española, si bien esta última no está del todo ausente, como se evidencia en la expresión "300 años de esclavitud”, que Soublette usara para referirse al colonialismo español.

Representante del espíritu republicano centenarista, de honda huella conservadora, pero claramente conciliatorio, la narrativa de Cromos evidencia también la distancia misma que el Partido Conservador había tomado frente al ala de la extrema derecha, configurada desde la década de 1920 por quienes precisamente fueran los grandes críticos de la generación y postura suprapartidista de los centenaristas, a saber, los jóvenes Leopardos, para quienes la falta de un claro rival político habría de producir aletargamiento en el entonces partido gobernante (Arias, 2007; Ayala, 2012). Sin duda, la división interna del Partido Conservador contribuyó al triunfo liberal en las elecciones de 1930. Sin embargo, al poder llegaría quien, apoyado, incluso por algunos conservadores, no marcaría una ruptura fuerte con el periodo anterior: Enrique Olaya Herrera. El número especial de Cromos se publica, justamente, cuatro meses después de la posesión como presidente de quien fuera un destacado miembro de la generación del Centenario; colaborador del gobierno de Carlos E. Restrepo, y artífice de una política de reformismo moderado denomi- 
nada concertación nacional. Un espíritu de conciliación suprapartidista la animaba, no obstante, el consenso en torno a él estuviera lejos del logrado en 1910 (Ocampo, 1999).

La distancia mencionada se evidencia, precisamente, en torno a la representación de Bolívar. Como sostiene Ayala (2012), "aunque peleaban por la herencia bolivariana desde los conservadores, hasta los comunistas, los nacionalistas insistirán en hacer parecer el ideario bolivariano suyo" ( $\mathrm{p}$. 568). En este sentido, si bien Cromos hace eco de la construcción de Bolívar como un semidiós o un hombre, cuya obra tanto de guerrero como de estadista daba cuenta de la mano de Dios, es decir, si bien hace eco de uno de los hilos conductores de la heroización de Bolívar por parte de la derecha colombiana, como muy bien lo ha demostrado Ayala, a partir de un exhaustivo análisis de prensa de las décadas de 1920 y de 1930, claramente se distancia de la construcción que del prócer hiciera la extrema derecha, en su afirmar que este nunca contemplara la opción monárquica.

La defensa de la monarquía como principio de salvación histórica, en el pasado, y de la democracia totalitaria, en el presente, que apoyarían Silvio Villegas y Gilberto Alzate Avendaño, entre otros líderes del fascismo colombiano, está ausente de las páginas del número especial de Cromos. Mientras que en Cromos se percibe una insistencia en afirmar los valores republicanos de Bolívar, Villegas no dudaría en afirmar: "La constitución de Bolivia que establecía, según apunta Arosemena, una monarquía sin nombre, fue el código más sabio que se constituyó para estas repúblicas en los días primeros de su vida independiente; ella hubiera evitado a estas democracias la crónica de sus infortunios" (citado por Ayala, 2012, p. 531).

El Bolívar de Cromos fue, entonces, un Bolívar republicano, que se oponía a la monarquía, porque siendo por naturaleza un césar o un dictador no necesitaba de un aval externo, una corona, por ejemplo, para ejercer como tal, como propondría, en "Pasión y muerte de Bolívar”, el español José María Salaverría (1873-1940). Si Bolívar, quien, según Salaverría, "personificaba el ideal de la libertad, el gesto redentor frente a la tiranía y el espíritu de viejos tiempos", hubiera sucumbido a la tentación de coronarse rey 
o emperador, solo habría añadido su nombre a la lista de los "aventureros históricos". "Bolívar recuerda más bien a César [... n nace para mandar. Es cesarista legítima y naturalmente. Y aunque le halague la idea de coronarse no se apresura a coronarse rey”. De ahí que, pese a su inclinación natural a la dictadura, Bolívar refutara la idea de ceñirse una corona. Sabiendo que la opción monárquica lo deshonraría ante el mundo, prefirió conservar el título de Libertador.

Otra manera de insistir en el republicanismo de Bolívar tenía que ver con explicar la construcción de su percepción como déspota, tras la proclamación de la Constitución de Bolivia, como producto de una lectura demasiado ortodoxa y apegada a la teoría. Este fue el argumento del poeta Eduardo Castillo en "La amable loca", donde sostiene que, "para un grupo de hombres poseídos por el más fiero puritanismo republicano, el Héroe, el Padre de la Patria, se había convertido en un déspota execrable”.

Finalmente, una tercera manera de insistir en la adhesión republicana y hasta democrática de Bolívar provendría de la pluma de Montalvo. En "Bolívar en Pativilca", desmentiría como falso el rumor en circulación a finales de la década de 1920 de que Bolívar hubiera contemplado el establecimiento de una monarquía constitucional, encabezada por un príncipe europeo. "Sus enemigos echaron en campaña la voz de la coronación por mano de las potencias europeas, cuando nada estuvo más lejos de su pensamiento. [... él siempre rechazó de buena fe tan indebidas ofertas. Su bandera había sido la de la democracia”.

\section{Conclusiones}

El número especial que Cromos dedicara en 1930 a celebrar el centenario de la muerte de Simón Bolívar pone de manifiesto cómo el proceso de heroización de quien se considerara el padre de la patria llevaba ínsito un conjunto de representaciones sobre la nación colombiana y, más ampliamente, sobre el continente americano. En la medida en que la oda a Bolívar suponía a su vez una oda a España, desde el punto de vista de la historia, la cultura y la raza, la alabanza a Bolívar dejaba en claro un desprecio por el pasado 
prehispánico y un desconocimiento de toda historia previa a la llegada de Colón. Admirar la capacidad del Libertador iba de la mano de la exaltación de la raza blanca europea, cuyas ventajas comparativas eran tan altas frente a otras - negra, indígena, mestiza y oriental - que justificaban cualquier esfuerzo genealógico requerido para demostrar, desde la vertiente española de cuño vasco, la blancura de Bolívar. El aprecio, teñido de devoción religiosa por el Libertador, suponía, en definitiva, exaltar la misión civilizadora de España en América, con la Iglesia católica como un actor principal. De manera concomitante, cuanto más alto se elevaba el Libertador, más bajo caían sus contemporáneos, convertidos en no más que obstáculos a superar para el logro de la gesta revolucionaria. Cuanto más crecía el Libertador, más grande se volvía la naturaleza del Nuevo Mundo; enorme y maravillosa como él. A su vez, cuanto más salvaje y en estado bruto la naturaleza se presentara, más superlativas resultaban las virtudes del hombre capaz de someterla. Por último, el Bolívar de Cromos era un Bolívar republicano que se oponía a la monarquía, o porque fuera un demócrata (como suponía Montalvo); o porque siendo por naturaleza un césar o un dictador no necesitara de un aval externo, una corona, por ejemplo, para ejercer como tal (como proponía Salaverría); o porque siendo demasiado ortodoxos, muy apegados a la teoría, quienes se opusieron a él lo vieron como un déspota (como planteaba Castillo).

\section{Referencias}

Ardila, H. y Vizcaíno, I. (2008). Hombres y mujeres en las letras colombianas. Bogotá, Colombia: Magisterio.

Arias Trujillo, R. (2007). Los Leopardos: una historia intelectual de los años 1920. Bogotá, Colombia: Universidad de los Andes.

Ayala Diago, C. A. (2012). Bolívar en la fabricación ideológica del fascismo colombiano. En B. Tovar Zambrano (Ed.), Independencia: historia diversa (pp. 523-591). Bogotá, Colombia: Universidad Nacional de Colombia. 
Banrepcultural. (s. f.). Eduardo Castillo. Recuperado de http://enciclopedia.banrepcultural.org/index.php?title=Eduardo_Castillo

Briceño, M. (1883). La campaña de Boyacá: fragmento de un tratado sobre estrategia. En A. Urdaneta (Ed.), Papel Periódico Ilustrado (pp. 382-386). Bogotá, Colombia: Imprenta de Silvestre y Compañía.

Campos-Rodríguez, D. (2012). El general en su laberinto como fuente histórica: salud, enfermedad y heroísmo. En B. Tovar Zambrano (Ed.), Independencia: historia diversa (pp. 257-279). Bogotá, Colombia: Universidad Nacional de Colombia.

Castro-Berrojo, L. (2008). Héroes y caídos: políticas de la memoria en la España contemporánea. Madrid, España: Catarata.

Castro-Gómez, S. (2009). Tejidos oníricos: movilidad, capitalismo y biopolítica en Bogotá (1910-1930). Bogotá, Colombia: Pontificia Universidad Javeriana.

Castro-Gómez, S. (2007). ¿Disciplinar o poblar? La intelectualidad colombiana frente a la biopolítica 1904-1934. Nómadas, 26, 44-55. Recuperado de http://nomadas.ucentral.edu.co/nomadas/pdf/ nomadas_26/26_5C_Disciplinaropoblar.pdf

Chalbaud-Zerpa, C. (1997). Historia de Mérida. Mérida, Venezuela: Universidad de los Andes.

Gerbi, A. (1973). The dispute of the new world: The history of a polemic, 17501900. Pittsburgh, EE. UU.: University of Pittsburgh Press.

Jiménez-Hernández, W. F. (2012). El Papel Periódico Ilustrado y la configuración del proyecto de la Regeneración (1881-1888). Historia Crítica, 47, 115-138. DOI: https://doi.org/10.7440/histcrit47.2012.07

Martínez-Simanca, A. (2004). Simón Latino y la librería de la Gran Colombia: patrimonio cultural de Bogotá. Bogotá, Colombia: Alcaldía Mayor. 
Melo, J. O. (2012). Bolívar en Colombia: memoria, historia y política. En J. C. Escobar Villegas, S. de Mojica y A. L. Salaza Maya (Eds.), Conmemoraciones y crisis: procesos independentistas en Iberoamérica y la Nueva Granada (pp. 293-309). Bogotá, Colombia: Pontificia Universidad Javeriana.

Melo, J. O. (2016). Bolívar en Colombia: conservador y revolucionario [Entrada blog]. Recuperado de http://www.jorgeorlandomelo.com/ bolivarcolombia.htm

Muñoz Rojas, C. (2011). Más allá del problema racial: el determinismo geográfico y las "dolencias sociales": estudio introductorio. En C. Muñoz Rojas (Ed.), Los problemas de la raza en Colombia (pp. 1158). Bogotá, Colombia: Universidad del Rosario.

Nieto Olarte, M. (2006). Orden natural y orden social: ciencia y politica en el Semanario del Nuevo Reyno de Granada. Madrid, España: Consejo Superior de Investigaciones Científicas.

Ocampo López, J. (1999). Colombia en sus ideas. Tomo 3. Bogotá, Colombia: Universidad Central

Ojeda Avellaneda, A. C. (2008). Presentación. En Una mirada intima al libertador en los dos últimos años de su vida pública, 1828-1830 (pp. 7-14). Bucaramanga, Colombia: Universidad Industrial de Santander.

Pratt, M. L. (1992). Imperial eyes: Travel writing and transculturation. Londres, RU: Routledge.

Rodríguez Ávila, S. P. (2017). Memoria y olvido: usos públicos del pasado desde la Academia Colombiana de Historia (1930-1960). Bogotá, Colombia: Universidad del Rosario.

Santos, E. y Vallenilla Lanz, L. (2014). Debate sobre el cesarismo democrático. Revista de Economía Institucional, 16(31), 313-330. 
Recuperado de http://www.scielo.org.co/scielo.php?pid=S012459962014000200014\&script=sci_arttext\&tlng=en

Vallejo, M. (2016a, septiembre 23). Crónica de una dama centenaria. Cromos, pp. 60-79.

Vallejo, M. (2016b, septiembre 23). Con la cultura en las Venas. Cromos, pp. 203-227. 